\title{
NOTES AND CORRESPONDENCE \\ Rainy Season at Beijing and Shanghai since 1736
}

\author{
Wei-Chyung WANG \\ Atmospheric Sciences Research Center, State University of New York, Albany, New York, USA \\ Quansheng GE
}

Institute of Geographical Sciences and Natural Resources Research, Chinese Academy of Sciences, Beijing, China

Zhixin HAO

Atmospheric Sciences Research Center, State University of New York, Albany, New York, USA

Institute of Geographical Sciences and Natural Resources Research, Chinese Academy of Sciences, Beijing, China

Jingyun ZHENG, Peiyuan ZHANG

Institute of Geographical Sciences and Natural Resources Research, Chinese Academy of Sciences, Beijing, China

and

\section{Simona SUNG}

College of Saint Rose, Albany, New York, USA

(Manuscript received 18 June 2007, in final form 3 July 2008)

\begin{abstract}
The rainy season is an important climate feature over Eastern China where anomaly in either its timing or length can lead to adverse economic and social consequences. Here, we illustrate that the records of daily precipitation description at Beijing and Shanghai contained in Memos-to-Emperor during the Qing Dynasty provide a unique source to extend the rainy season information to 1736 . The information together with the instrument measurements since 1875 in both cities reveals significant inter-annual and decadal variations of the beginning and ending dates, and length of the rainy season. The analysis further reveals that, on the decadal time scale, the length of the rainy season increased in Shanghai since 1961 with more frequent extreme rainfall events, but decreased in Beijing since 1975 with persistent dry conditions. This pattern of changes was not seen in any other periods of the data, in particular during 1736-1820 when both cities showed an increase in the length of the rainy season.
\end{abstract}

Corresponding author: Wei-Chyung Wang, Atmospheric Sciences Research Center, State University of New York at Albany, 251 Fuller Road, Albany, NY 12203, USA

E-mail: wang@climate.cestm.albany.edu (C)2008, Meteorological Society of Japan 


\section{Introduction}

The distribution of summer precipitation in East China is dominated by the East Asian summer monsoon (EASM) which, after onset in early May in the South China Sea, migrates northward reaching North China in early August, and starting September moves rapidly southward. The EASM advance and withdraw produce a unique feature of "rainy season"-about six weeks in North China, three weeks in the middle and lower reaches of Yangtze River Valley (MLRYRV), and five weeks in South China (Tao and Chen 1987; Qian et al. 2002; Ding and Chan 2005).

The timing and length of the rainy season are important for at least two reasons. First, precipitation during the rainy season accounts for 50$60 \%$ of the annual total in North China, $15-30 \%$ in MLRYRV, and $40-50 \%$ in South China. The years when anomaly occurred, flood/drought conditions often prevailed (Ding 1994; Tao and Chen 1987; Wang et al. 2000). Secondly, the timing (starting and ending dates) of the rainy season is critical for crop planting and yields (Griffiths 1994; Tao et al. 1997).

Here we used the descriptions of the daily precipitation events, dated as early as 1736 , in the historical documents "Memos-to-Emperor" during the Qing Dynasty (Ge et al. 2005) to extract the rainy seasons around Beijing and Shanghai. The quantitative information together with values derived from available instrument measurements since 1875 provide long-term data for studying rainy season variations in these two sites. While Ge et al. (2008) used the historical documents to reconstruct "Meiyu season" for the whole MLRYVR which includes Shanghai, the focus in this study is on the contrast in "rainy season" between Shanghai and Beijing.

Below we first introduce the historical data, next describe the methodology to extract the starting and ending dates from both the instrument measurements and historical documents, and finally discuss the highlights of the inter-annual and decadal variations of the rainy season since 1736 .

\section{Precipitation records in Memos-to- Emperor}

The daily weather conditions over China came to be routinely reported in the "Memos-to-Emperor" since 1736 of the Qing Dynasty (1644-1911). The majority of the memos are stored in the First
Historical Archive in the Beijing Palace Museum while a small number were published by the Taipei Palace Museum (Ge et al. 2005). Since the mid 1970 s, a concerted effort by the researchers from the Institute of Geography (now the Institute of Geographical Sciences and Natural Resources Research), Chinese Academy of Sciences, has painstakingly sifted through the historical records to extract the weather-related information contained in " $Y u$ (rainfall)-Xue (snowfall)-Fen (Chinese precipitation measure, approximately $0.32 \mathrm{~cm}$ )Cun (10-Fens)". The weather conditions recorded the beginning and ending dates, duration, and soil infiltration depth of rain or the depth of snow on surface for individual precipitation events at designated sites. Consequently, the rain-days (days with rain) are readily available; for instrumental data, the rain-day is the day with daily rainfall $\geq 0.1 \mathrm{~mm}$.

The Yu-Xue-Fen-Cun records, available for 273 sites from 1736 to 1911, exhibit quite uneven temporal and spatial distributions (Ge et al. 2005). In particular, the records after 1820 were less specific in providing the daily information; therefore, the present study focuses on the period 1736-1820. Furthermore, we choose Beijing and Shanghai because, in addition to Yu-Xue-Fen-Cun, instrument measurements of daily precipitation since 1875 were compiled by Beijing Meteorological Bureau (1982) and Shanghai Meteorological Bureau (1971), respectively. But more importantly, as shown in Fig. 1, the two locations have climatological significance because Beijing locates on the north edge of the EASM (Zhu and Wang 2002; Chen et al. 2004; Wang and Zhou 2005), while Shanghai is influenced by Meiyu, a unique climatic characteristics over MLRYVR (see below for more discussion of both aspects). Since the Yu-Xue-FenCun records cover an area with inherently a spatial scale larger than a single measurement station, we have chosen extra stations Tianjin and Baoding near Beijing, and Suzhou and Liyang near Shanghai when instrument data were available (see Fig. 1). Note that, because of the theft, fire and other disasters, there are missing records in some years, notably eleven years $(1751-52,1764,1773,1783$, 1789, 1802, 1815, 1817 and 1819-20) in Shanghai, and six years (1751-52, 1758, 1802 and 1819-20) in Beijing.

For the period 1875-1911 when both the Yu-XueFen-Cun and instrument measurements existed, we found the consistency in rain-day information to be extremely high. For example, for Beijing in 


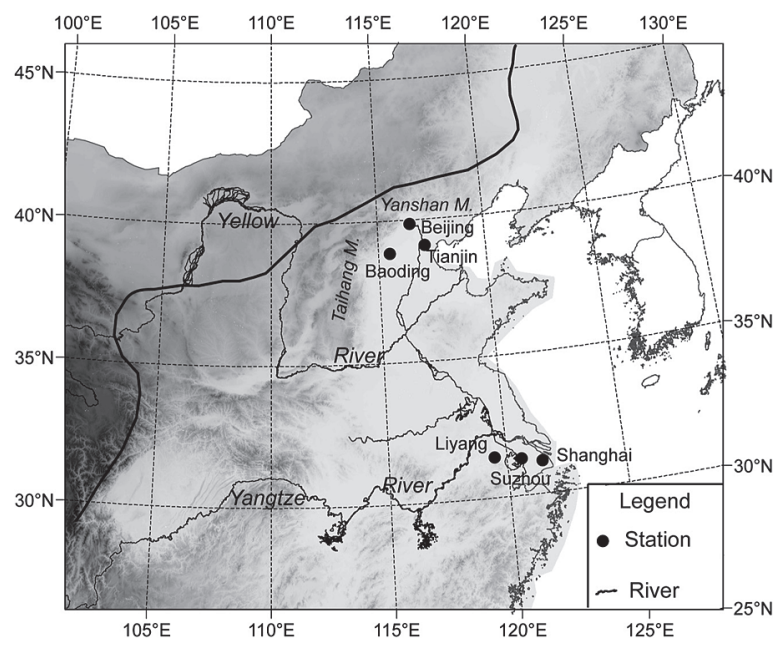

Fig. 1. The sites where the Yu-Xue-FenCun records and meteorological observations are used in the study. The heavy line borders the north region of the East Asia summer monsoon (EASM; Editorial Board of China Physical Geography 1985). The light-to-dark shading indicates the low-to-high elevation. The three stations, Shanghai $\left(31.17^{\circ} \mathrm{N}, 121.43^{\circ} \mathrm{E}\right)$, Suzhou $\left(31.06^{\circ} \mathrm{N}, 120.43^{\circ} \mathrm{E}\right)$ and Liyang $\left(31.43^{\circ} \mathrm{N}, 119.48^{\circ} \mathrm{E}\right)$ are located in the transition zone of EASM. Because of the Yanshan mountain in the north and Taihang mountain in the west, the three stations, Beijing $\left(39.8^{\circ} \mathrm{N}, 116.47^{\circ} \mathrm{E}\right)$, Tianjin $\left(39.1^{\circ} \mathrm{N}, 117.17^{\circ} \mathrm{E}\right)$ and Baoding $\left(38.85^{\circ}\right.$ $\mathrm{N}, 115.52^{\circ} \mathrm{E}$ ) are sitting along the border of the north reach of the EASM. The distance from Beijing is $120 \mathrm{~km}$ for Tianjin and $137 \mathrm{~km}$ for Baoding; from Shanghai is $80 \mathrm{~km}$ for Suzhou and $200 \mathrm{~km}$ for Liyang.

1883: (1) the Imperial Edicts of Guangxu Emperor read: "The capital (Beijing) did not receive enough rain yet since this summer. And the rain was heavy from the Haishi (Chinese ancient time: 9:00-11:00 pm) of the 4th to Shenshi (3:00-5:00 pm) of the 5th, the sixth month in lunar calendar (7/7-8)", for which the measurements of rainfall during the two days indicated 9.2 and $13.5 \mathrm{~mm}$ respectively; and (2) on the first day of the seventh month (in lunar calendar), the ninth year of Guangxu emperor (3 August 1883), Zaizhuo, Kuiying, and Shaoqi reported "It was raining from Shenshi on 16th (7/19), and never ended until the Wushi (11:00 am-1:00 pm) on $26^{\text {th }}$ of the sixth month (7/29), the areas near the imperial palace and royal cemetery (covering Beijing and its surrounding areas) all received enough rain", which were also found in the daily precipitation of $44.5,19.1,0,0,5.3,126.8,79,5.1$, 19.6, 49.8, and $224.7 \mathrm{~mm}$ during July $19-29$.

\section{Starting and ending dates}

As shown in Fig. 1, EASM covers eastern China, Korea, Japan, and the adjacent marginal seas (Editorial Board of China Physical Geography 1985), and its temporal movement directly affects the length of the rainy season. The rainy season in Shanghai and Beijing are dominated by the evolution of large-scale circulation (Tao and Chen 1987). Specifically, when the western Pacific subtropical high jumps northward around mid-June with its ridge locating around $20-22^{\circ} \mathrm{N}$, the rainy season begins in Shanghai. Subsequently, the subtropical high jumps northward again around early-July with the ridge advanced to $\sim 30^{\circ} \mathrm{N}$, the rainy season of Beijing starts. The presence of Yanshan Mountain (north of Beijing) and Taihang Mountain (west of Beijing) blocks the northward movement of EASM. Beijing, located at the north edge of the EASM, is therefore in a transition zone between the sub-humid and semi-arid climate regions.

To extract the rainy season, we need first to establish a consistent criterion for quantitatively defining the starting and ending dates from both instrumental measurements and Yu-Xue-Fen-Cun records. There have been many approaches to define these dates, mainly by an abrupt change in either the amount/number of rain-days or atmospheric circulation (Zhao 1994; Samel et al. 1999; Wang and Linho 2002; Zeng and Lu 2004). Here, we define the dates by identifying the changes in slope of the linear trend of the accumulated precipitation using the 1951-2000 daily mean precipitation from May through September (http://cdc.cma. gov.cn/shuju/index3.jsp?tpcat=SURF\&dsid=SUR F_CLI_CHN_MUL_DAY). As shown in Fig. 2, we adopted the following definition: the "beginning/ ending" of the rainy season during May-September period are identified to be the "first/last" date of the "first/last" time when a specified number (four for Beijing and five for Shanghai) of rain-day was found within a ten-day span. For Shanghai, we further impose the conditions that the number of continuous rainless days should be less than 5 days; and that at least 6 rain-days occurred, otherwise, it will be a year without rainy season (Xu 1965; Zhang and Wang 1991). The rainy season, shown in Fig. 2 

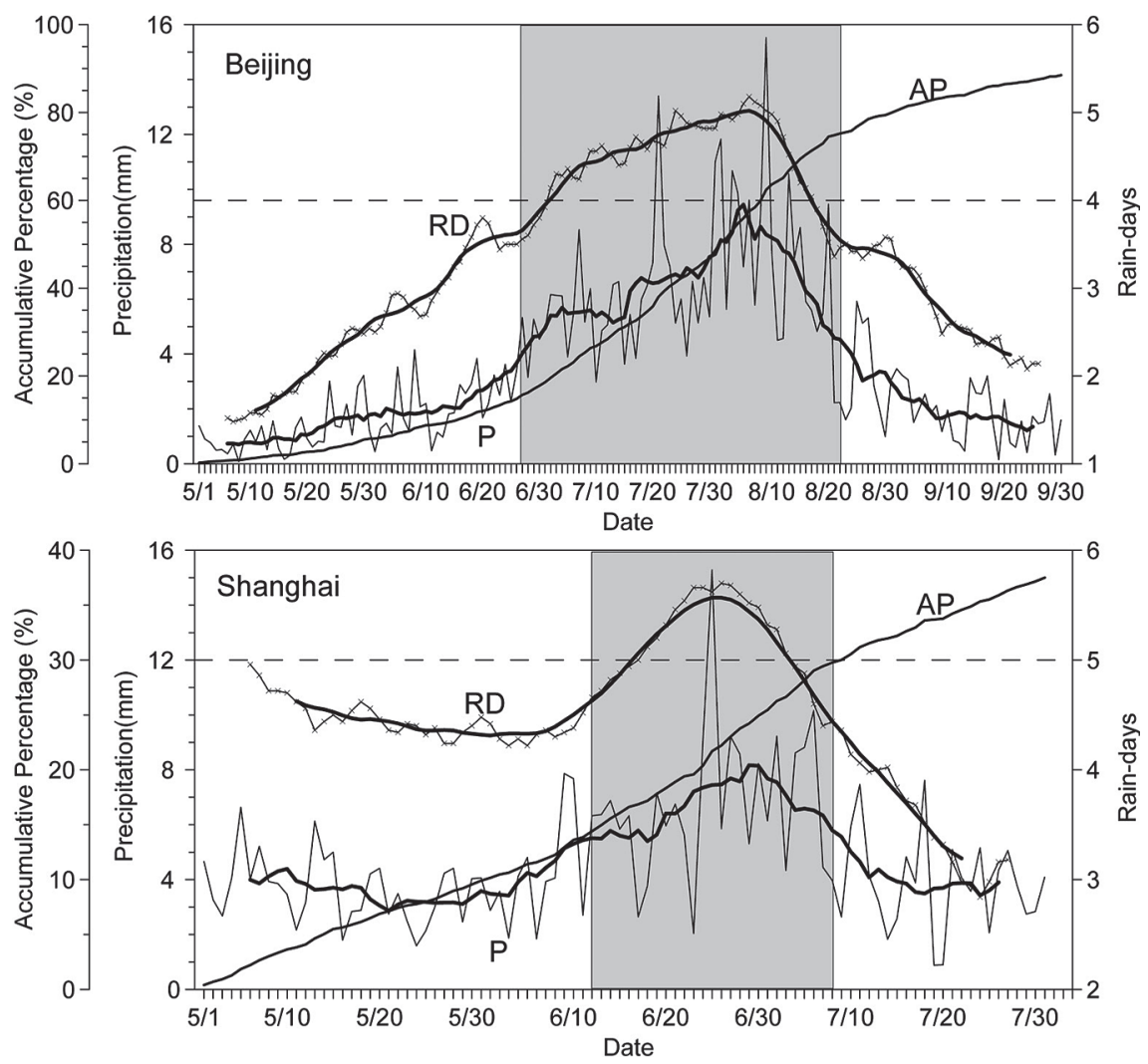

Fig. 2. The 1951-2000 mean daily precipitation (P, mm), the number of rain-day (RD) within the consecutive ten-day period, and the accumulated precipitation (AP, \% of annual total) between May 1 and the indicated date. The heavily lines are 5-days running means. The shaded period is the rainy season when the RD is greater than 4 for Beijing and 5 for Shanghai (see Table 1 for the stations used around Beijing and Shanghai for better spatial representation).

and listed in Table 1, is therefore June 27-August 22 for Beijing and June 12-July 8 for Shanghai. As will be discussed further below, the starting and ending dates showed large inter-annual variability, about 15 days for Beijing and 10 days for Shanghai. The total precipitation within the rainy season is calculated to be $373 \mathrm{~mm}$ for Beijing and $183 \mathrm{~mm}$ for Shanghai, which accounts for $60 \%$ and $16 \%$ of their respective annual totals.

As indicated in Table 1 , there exists spatial variability in the precipitation characteristics of Beijing and Shanghai when compared with their respective neighboring stations. To consider this aspect, we define the starting/ending dates of the rainy season for the individual year of the period 1951 -2000 to be the respective dates contained in two of the three stations. For example, using the mean statistics listed in Table 1 for Beijing, Tianjin and Baoding, the starting/ending dates would be June
Table. 1. The characteristics of the rainy seasonstarting date (SD), ending date (ED), total rainfall amount $(\mathrm{Q}, \mathrm{mm})$, and the ratio $(\mathrm{R}, \%)$ of total rainfall in the rainy season to annual total-for the six stations shown in Fig. 1. Values in parentheses are the variances of the time series. The statistics are calculated using the 1951-2000 precipitation measurements.

\begin{tabular}{ccccc}
\hline & SD & ED & Q & R \\
\hline Beijing & $6 / 27(15)$ & $8 / 22(14)$ & 373 & 60 \\
Tianjin & $6 / 28(17)$ & $8 / 17(11)$ & 296 & 54 \\
Baoding & $7 / 3(13)$ & $8 / 18(12)$ & 278 & 50 \\
\hline Shanghai & $6 / 12(10)$ & $7 / 8(10)$ & 183 & 16 \\
Suzhou & $6 / 16(9)$ & $7 / 10(11)$ & 167 & 14 \\
Liyang & $6 / 19(9)$ & $7 / 10(11)$ & 177 & 15 \\
\hline
\end{tabular}


28/August 18. As it turns out, in most cases, Beijing/Shanghai is one of the two chosen stations, which also provide a good rationale for using the Beijing and Shanghai 1875-1950 data to identify the starting/ending dates of the rainy season because the data for the neighboring stations are not available. We have also found that the variability and trend during 1951-2000 are quite close between the choice of two stations versus directly using the Beijing and Shanghai station individually.

Because of the explicit description of the precipitation events, the rainy season can be readily identified from the Yu-Xue-Fen-Cun records. For example, in Shanghai, the memo by Ming De, General Governor of Jiangsu province, reported in the thirty-first year of Emperor Qianlong (1766), "it was plum season, the rain did not stop from June 2 to 16, then, alternated by rain and sun, until June 30 , the rain stopped and the sky was shinning."; the period of rainy season in that year was June 2-29. The empty rainy season can also be inferred from the records. For example, in the sixth year of Emperor Qianlong (1741), Yang Chaohui, the Liangjiang Governor administering the Jiangsu and Anhui Provinces, and Shanghai city, reported on the $24^{\text {th }}$ of the sixth month (August 5), "Nanjing and Zhenjiang (close to Suzhou and Liyang) were both lack of rain during the last 2 months (from June 7 to August 5). Recently, they only got 1-2 cun of rain, the moisture was not enough"; Li Ying, the textile officer, reported on the $10^{\text {th }}$ of the seventh month (August 20), "Nanjing was sunny since the fifth and sixth months (June 13 to August 10), and the farmers were pleading for rain urgently". In Beijing and the neighboring area, the starting and ending dates of the rainy season are usually explicitly recorded. For example, in 1740, the following are 2 reports by Sun Jiagan, the General Governor of Zhili province, "In 1740, 10-Fu and 5-Zhou (Fu and Zhou both are administrative regions) all got the continuous rainfall from June 18 to 24; Reported on August 19, "There was enough rain during June 29-30, July 4-5; and it rained in the whole Zhili province during July 9-11, 18-21; during July 25-27, the rain was particularly heavy and continuous." After July 27 , no rainfall was recorded till the autumn. So the rainy season was identified to be June 18-July 27 .

\section{Variability}

Using the criterion discussed above, we have derived the starting and ending dates of rainy season for Beijing and Shanghai since 1736. As illustrated in Fig. 3, both dates show large interannual variability without a clear trend except for the period 1961-2000 in Shanghai where the starting date remained relatively unchanged but the ending date had a trend of being delayed, and for the period 1975-2000 in Beijing where the starting date was delayed and the ending date advanced. As shown in Fig. 3, the resulting rainy season length also showed substantial inter-annual variability. For Shanghai, three regimes existed, a slight increasing trend during 1736-1820, relatively constant with large variability during 1875-1960, and an increasing trend 0.32 days/year afterwards with the correlation coefficient 0.33 . The length of rainy season had similar characteristics in Beijing except that there was a decreasing trend 1.14 days/year starting since 1975, with the correlation coefficient 0.43 , and these trends are statistically significant at 95\% confidence level. Note that the length is positively correlated with the ending date in Shanghai, but negatively correlated with the starting date in Beijing, with correlation coefficient 0.61 and 0.77 , respectively. On the other hand, the correlation is negative in Shanghai for the starting date, but positive in Beijing for the ending date, with correlation coefficient 0.48 and 0.59 , respectively.

Two characteristics of the rainy season in Beijing and Shanghai are noted here. First, power spectral analysis reveals that the rainy season in Beijing during 1736-1820 shows statistically significant inter-annual variations with 5-year and quasi 2-year cycle, and Shanghai shows quasi 2-year cycle, passing 95\% confidence level; the latter is consistent with the EASM index during 1873-2000 (Guo et al. 2004). Secondly, differences exist in the length of rainy season between the $20^{\text {th }}$ century (1915-2000) and the $18-19^{\text {th }}$ century. While the mean length differs by 2 days for Beijing and 0.5 days for Shanghai; the means of starting date is identical and ending date in earlier time is delayed by 2-day for Beijing, but both advanced 2- and 3-day for Shanghai.

Figure 3 also reveals some extreme events. For example, the most severe flood of the $20^{\text {th }}$ century occurred in 1954 (Luo and Yue 1996) when Shanghai had $531 \mathrm{~mm}$ rainfall in 57 days and Beijing had $728 \mathrm{~mm}$ in 82 days; during July-August, the flood along the Yangtze, Huaihe and Haihe Valley affected over 19 million people with 31,000 people perished. On the other hand, 1965 had the shortest rainy season, only 10 days (with $36 \mathrm{~mm}$ ) in Beijing and no rainy season in Shanghai. In the 

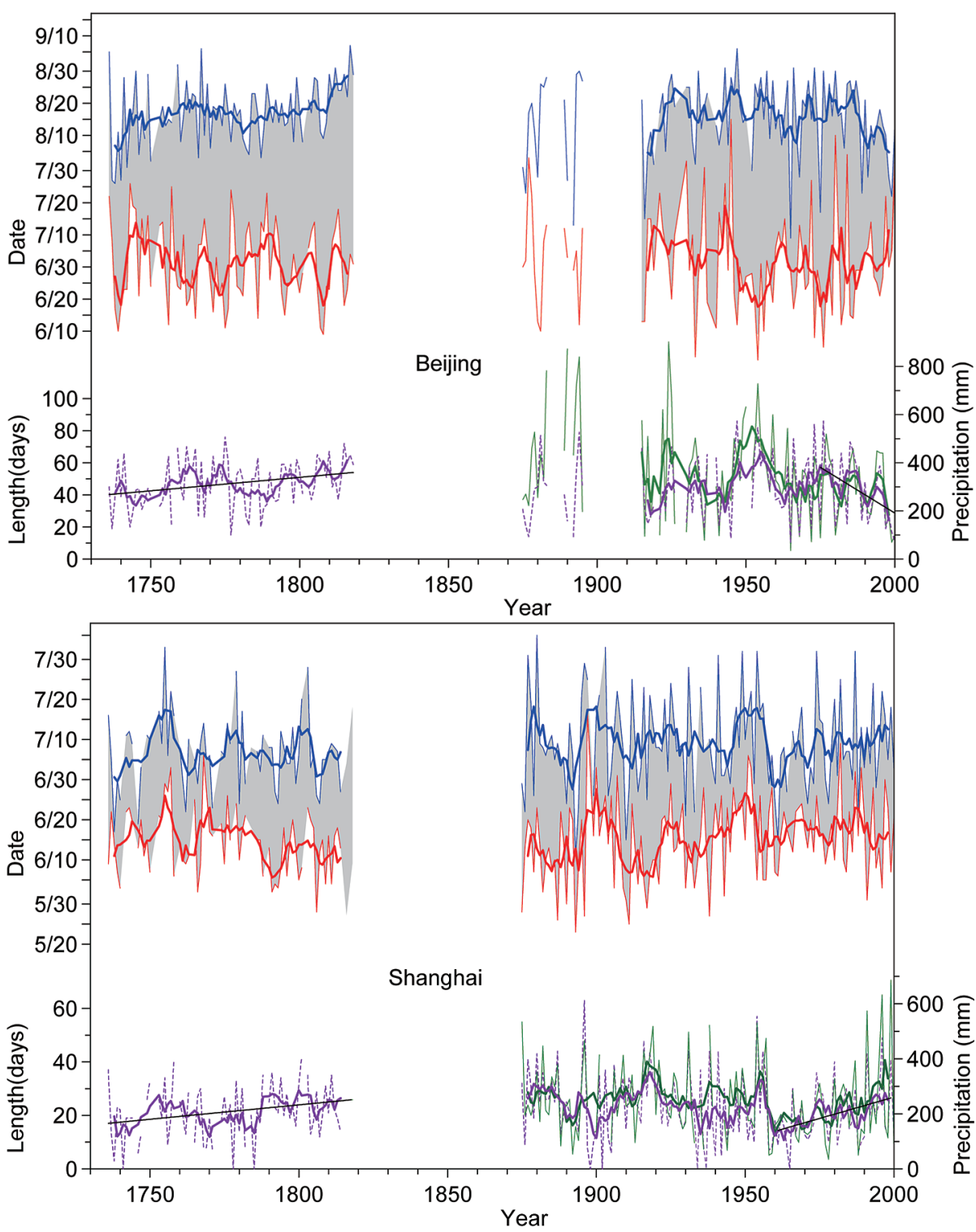

Fig. 3. Five-years running mean starting date (red line) and ending date (blue line) of the rainy season, length of the rainy season (purple), and total rainfall amount (green line) within the rainy season for Beijing and Shanghai. The yearly data is based on: Yu-Xue-Fen-Cun records for $1736-1820$, the measurements at the two stations for 1875-1950, and the stations listed in Table 1 for 1951-2000. Note that the daily precipitation data for 1875-1950 are available for Shanghai and Beijing, although for the latter location data are missing during 1884-88, 1896-1914, 1927-29, 1938-39. Linear trend of rainy season length is marked during 1736-1820 and 1975-2000 for Beijing, and 1736-1820 and 1961-2000 for Shanghai.

earlier times, 1775 had the longest rainy season of 76 days and the heavy precipitation led to severe flood described as, "heavy rainfall started on the 7 -8th of seventh month (August 2-3), and the north and south dike of the Yongding River was broken. The workers were repairing and rebuilding the dike"; "continuous heavy rainfall caused the rivers to rise from the beginning of seventh month, many counties located at the lower reaches were flooded"; "prayer for sunshine continued till the third of August (August $28)$ ". We have also compared, between the historical times and the recent decades, the frequency 
of extreme rainy seasons, defined here as the occurrence rate of $1 / 10$-years. The data indicate that, except for extremely short length of rainy season in Shanghai, the others are all less frequent during historical times.

On the multi-decadal time scales, the rainy season in Shanghai showed characteristics of: a slightly increasing trend during 1736-1820; after 50-year of data gap, a 40-year oscillation during 1875-1955; and a clear increasing trend since 1961. In Beijing, three regimes are identified: an increasing trend during 1736-1820; after 95-year of data gap, an increasing trend in 1915-1955; and a clear decreasing trend started in 1975. Although the rainy seasons in Beijing and Shanghai were both influenced by the EASM, the spatial pattern of the length of rainy season on the decadal time scale showed similarities during 1736-1750, 1781-1820, 18811890 and 1951-1980, but differences during 17511780, 1911-1950 and 1981-2000. Perhaps the most intriguing feature of the decadal variation illustrated in Fig. 3 is that a divergent trend emerged for Beijing and Shanghai during recent decades: the ending dates of rainy season have been consistently pushing back since 1961 in Shanghai making the rainy season longer, and a concurrent late start and early ending dates in Beijing since 1975. This feature was nevertheless consistent with decadal variations in EASM in both its northern boundary and intensity since 1961 documented by Jiang et al. (2006). Note however that analyzing the data of Zheng et al. (2006) indicate this divergence also occurred before 1736, notably during 1180-1200, $1450-1480$ and $1690-1720$.

It is expected that the rainfall amount within the rainy season is closely related to the length of the rainy season, and the 1951-2000 data indicate that the correlation is indeed high, 0.86 for Shanghai and 0.83 for Beijing, significant at $95 \%$ confidence level, which could be used to reconstruct the precipitation during the rainy season. Furthermore, the 1951-2000 data indicate that there also exists a good correlation between the amount of rainfall during the rainy season and the total amount of annual rainfall for Beijing (see Table 1), but not for Shanghai because the typhoons (occurred mainly in August and September) and spring rain contribute significantly to the annual total.

\section{Remarks}

Note that the criterion of five rainy-days for Shanghai based on daily precipitation characteris- tics studied here is different from Ge et al. (2008)'s criterion of six rainy-day which is the officially designated value by the National Climate Center of the China Meteorological Administration (http://ncc. cma.gov.cn/Monitoring/Bulletin/200602/history bulletinc.htm) for the whole MLRYRV. Consequently, difference in characteristics does exist between the Shanghai rainy season and the regional Meiyu season reported in Ge et al. (2008); for example, during 1736-1820, the rainy season showed an increasing trend somewhat larger than the Meiyu season.

The rainy season reconstruction effort is currently on-going for other sites, in particular those located in MLRYRV, a transition region in the annual north-south migration of the East Asia summer monsoon. The spatial pattern of rainy season, in addition to directly providing the rain belt movement in 18 and $19^{\text {th }}$ centuries, may also facilitate the study of other relevant climate parameters, such as the western Pacific subtropical high (Ding 1994), Equatorial eastern Pacific sea surface temperature (Chang et al. 2000; Lau and Weng 2001) and the snow volume on the Tibet plateau (Wu and Qian 2003; Zhang et al. 2004). Nevertheless, the mechanisms to explain the pattern of change in rainy season in Beijing and Shanghai in recent decades remain to be investigated, mostlikely caused by a combination of changes in the relevant climate parameters mentioned above.

\section{Acknowledgements.}

This research was supported by grants to IGSNRR from the Chinese Academy of Sciences (KZCX2-YW-315-2), National Natural Science Foundation of China (40701021, 40625002, and 40331013), and to SUNYA from the Office of Sciences, Department of Energy. ZXH was a visiting Postdoctoral Research Associate at SUNYA, sponsored under the "Climate Science" agreement between China's Ministry of Sciences and Technology and the U. S. Department of Energy.

\section{References}

Beijing Meteorological Bureau, 1982: Beijing meteorological data (1841-1980). Beijing Meteorological Bureau, Beijing, 500 pp (in Chinese).

Chang, C.-P., Y.-S. Zhang, and L. Tim, 2000: Interannual and interdecadal variations of the East Asian summer monsoon and tropical Pacific SSTs. Part I: Roles of the subtropical ridge. J. Climate, 13, 4310-4325. 
Chen, T.-C., S.-Y. Wang, W.-R. Huang, and M.-C. Yen, 2004: Variation of the East Asian summer monsoon rainfall. J. Climate, 17, 744-762.

Ding, Y.-H., 1994: Monsoons over China. Kluwer Academic Publishers, Boston, 419 pp.

Ding, Y.-H. and J.C.L. Chan, 2005: The East Asian summer monsoon: An overview. Meteor. Atmos. Phys., 89, 117-142.

Editorial Board of China Physical Geography, 1985: General introduction to physical geography of China. Science Press, Beijing, 413 pp. (in Chinese)

Ge, Q.-S., J.-Y. Zheng, Z.-X. Hao, P.-Y. Zhang, and W.-C. Wang, 2005: Reconstruction of historical climate in China: High-resolution precipitation data from Qing dynasty archives. Bull. Amer. Meteor. Soc., 86, 671-679.

Ge, Q.-S., X.-F. Guo, J.-Y. Zheng, and Z.-X. Hao, 2008: Meiyu in the middle and lower reaches of the Yangtze River since 1736. Chinese Science Bulletin, 53, 107-114.

Griffiths, J.F., 1994: Handbook of Agricultural Meteorology. Oxford University Press, New York, Oxford, $320 \mathrm{pp}$.

Guo, Q.-Y., J.-N. Cai, X.-M. Shao, and W.-Y. Sha, 2004: Studies on the variations of East Asian summer monsoon during A.D. 1873-2000. Chin. J. Atmos. Sci., 28, 206-215 (in Chinese).

Jiang, Z.-H., J.-H. He, J.-P. Li, J.-H. Yang, and J. Wang, 2006: Northerly advancement characteristics of the East Asia summer monsoon with its interdecadal variations. Acta Geog. Sin., 61, 675-686 (in Chinese).

Lau, K.-M. and H. Weng, 2001: Coherent modes of global SST and summer rainfall over China: An assessment of the regional impacts of the 199798 El Niño. J. Climate, 14, 1294-1308.

Luo, C.-Z. and J.-X. Yue, 1996: Large Flood in China. China Bookstore Publication, Beijing, 434 pp (in Chinese).

Qian, W., H.-S. Kang, and D.-K. Lee, 2002: Distribution of seasonal rainfall in the East Asian monsoon region. Theor. Appl. Climatol., 73, 151-168, doi: 10.1007/s00704-002-0679-3.

Samel, A.N., W.-C. Wang, and X.-Z. Liang, 1999: The monsoon rainband over China and relationships with the Eurasian circulation. J. Climate, 12, 115131.

Shanghai Meteorological Bureau, 1971: Shanghai daily meteorological data. Shanghai Meteorological
Bureau, Shanghai, 245 pp (in Chinese).

Tao, S.-Y. and L.X. Chen, 1987: A review of recent research on the East Asian summer monsoon in China. In: Chang, C.-P. and T.N. Krishnamurti (eds.), Monsoon Meteorology. Oxford University Press, New York, Oxford, 60-92.

Tao, S.-Y., J.-S. Li, and A.-S. Wang, 1997: Eastern Asian monsoon and the disaster of flood/drought. $\mathrm{Di}$ saster Reduction in China, 7, 17-24 (in Chinese).

Wang, B. and Linho, 2002: Rainy season of the AsianPacific summer monsoon. J. Climate, 15, 386398.

Wang, W.-C., W. Gong, and H.-L. Wei, 2000: A regional model simulation of the 1991 severe precipitation event over the Yangtze-Huai River valley. Part I: Precipitation and circulation statistics. J. Climate, 13, 74-92.

Wang, Y.-Q. and L. Zhou, 2005: Observed trends in extreme precipitation events in China during 1961 -2001 and the associated changes in large-scale circulation. Geophys. Res. Lett., 32, doi:10.1029/ 2005GL022574.

Wu, T.-W. and Z.-G. Qian, 2003: The relation between the Tibetan winter snow and the Asian summer monsoon and rainfall: An observational investigation. J. Climate, 16, 2038-2051.

Xu, Q., 1965: The plum rain (Meiyu) of the middle and lower Yangtze Valley for recent 80 years. Sin. Meteorol. Acta., 35, 507-518 (in Chinese).

Zeng, X. and E. Lu, 2004: Globally unified monsoon onset and retreat indexes. J. Climate, 17, 22412248 .

Zhang, D.-E. and P.-K. Wang, 1991: A study on Meiyu activity of eighteenth century in the lower Yangtze region. Sci. in China (Ser. B), 34, 1237-1245.

Zhang, Y.-S., T. Li, and B. Wang, 2004: Decadal change of the spring snow depth over the Tibetan Plateau: The associated circulation and influence on the East Asian summer monsoon. J. Climate, 17, 2780-2793.

Zhao, H.-G., 1994: The rainy season in North China. The Meteorology, 20, 3-8 (in Chinese).

Zheng, J.-Y., W.-C. Wang, Q.-S. Ge, Z.-M. Man, and P.-Y. Zhang, 2006: Precipitation variability and extreme events in Eastern China during the past 1500 years. Terr. Atmos. Ocean, 17, 579-592.

Zhu, J.-H. and S.-W. Wang, 2002: 80 year oscillation of summer rainfall over North China and East Asian summer monsoon. Geophys. Res. Lett., 29, doi: 10.1029/2001GL013997. 